\title{
Regulation of online gambling
}

\author{
Ingo Fiedler ${ }^{1,2 *}$ \\ ${ }^{1}$ Universität Hamburg, Hamburg, Germany \\ ${ }^{2}$ Concordia University, Montreal, Canada
}

Received: 7 August 2018

Revised: 5 November 2018

Accepted: 5 November 2018

\begin{abstract}
Most of the existing research on gambling regulation refers to offline gambling. Yet online gambling is quickly becoming the predominant form and, moreover, is markedly different from offline gambling in many respects, which implies that the policy implications cannot readily be transferred from one sector of the gambling industry to the other. This paper argues that there is a significant research gap with respect to the optimal regulation specifically of online gambling. It appears likely that the vast differences in regulatory approaches to online gambling between countries and even within nation states are mostly attributable to a lack of knowledge regarding the idiosyncrasies of online gambling, rather than to differences in social attitudes towards gambling.
\end{abstract}

Keywords: gambling regulation; online gambling; public health; public order; external costs JEL Classification Codes: I18, L5, L8

\section{Introduction}

In most parts of the world, gambling is considered a demerit good that creates social costs which justify regulatory intervention in its market. The second section of this paper will go into more detail regarding the three major motives to regulate gambling. In conjunction with social attitudes towards gambling that vary over time and around the world, these motives have given rise to a diverse range of regulatory responses. Five broad approaches to gambling regulation can be distinguished: (1) A free market with only minor restrictions, e.g. casino gambling in Nevada or online gambling in the UK; (2) a liberal licensing system for private operators with some restrictions, e.g. online gambling in Italy and Denmark, or slot machines in Germany; (3) a restrictive licensing system; e.g. online poker and online sports betting in France; (4) a state monopoly, e.g. online gambling in Finland and Norway or lotteries and online poker in Québec; (5) a prohibition, e.g. all gambling in Utah or online casino gambling in France.

While gambling regulation in any given jurisdiction has always been subject to change, the

*E-mail: ingo.fiedler@uni-hamburg.de.

Citation: Fiedler, I. (2018) Regulation of online gambling, Economics and Business Letters, 7(4), 162-168. 
rapid rise of online gambling creates additional pressure for regulatory reform. For example, online gambling already accounts for more than half of the total gaming revenue in Denmark and the UK, with a strong upward trend (Danish Gambling Authority, 2018; Gambling Commission, 2018). Furthermore, in many jurisdictions, a large part of the online market is unregulated, for example between $83 \%$ and $90 \%$ of online poker in Québec (Kairouz et al., 2018) or $100 \%$ of the online casino market in France and Germany. Thus, regulatory enforcement is a particularly pressing issue in online gambling.

Although the motives to regulate gambling apply equally to the offline and the online sector, a number of idiosyncrasies of the latter suggest that specific regulatory responses are warranted. Section 3 shows the most important ways in which online gambling differs from offline gambling and how these differences relate to the three motives for regulation. Furthermore, some implications for optimal online gambling regulation are worked out.

Finally, Section 4 summarizes the findings and calls for additional research effort into online gambling regulation, on a two-fold basis: Firstly, most of the existing research on gambling and regulatory frameworks still focuses on offline gambling, ignoring the recent and rapid evolution and the particularities of online gambling. Secondly, considering the relative homogeneity among Western cultures, the observed differences among the implemented regulatory frameworks for online gambling are striking and suggest a lack of knowledge on the subject matter.

\section{Reasons to regulate gambling}

From an economic point of view, a welfare-optimizing state should not intervene in markets that are complete and without externalities, since any equilibrium produced by such markets will be Pareto optimal. Regulatory intervention is however justified if the markets cause externalities and if the intervention increases social welfare. Altogether banning a market is justified if the social cost created by the market exceeds its benefits (and if this shortfall exceeds the net cost of an illegal market that might evolve under a ban).

The social costs of gambling arise from two sources: (1) from the costs that compulsive gambling imposes on the player herself (because in contrast to the assumptions of classical welfare theory she is not fully rational and her preference function is not continuous and locally nonsaturated), her environment and society at large, and (2) from the associated crime in the form of delinquency, fraud, money laundering, and match fixing (Fiedler, 2016). In this context, costs should be understood in a broad sense, including also non-monetary and intangible aspects like mental illness caused by gambling addiction or the reduced enjoyment of supporters whose sport is undermined by match fixing.

While taxation can be regarded as a type of market intervention to reduce output and thus internalize external costs (Pigouvian tax), the public revenues derived from gambling constitute a significant contribution to public finance in many jurisdictions. Fiscal interests are thus considered a third reason for the regulation of gambling. Each of these reasons is analyzed in detail below.

\subsection{Consumer Protection and Public Health}

Pathological gambling is recognized as a mental disorder by the American Psychiatric Association and can entail a range of issues in the cognitive, mental, behavioral, social and economic spheres. These problems often compound each other, resulting in a negative spiral that can cause private, work-related and health crises (Braun et al., 2013).

Many addicted gamblers are so heavily indebted that they seek credit counseling services or file for personal bankruptcy (So and Kwok, 2006). The mental preoccupation with gambling leads pathological gamblers to neglect their work duties and often ultimately to lose their jobs (Steppan et al., 2010) or even their homes (Crane et al. 2005).

Impaired health can result indirectly from comorbidities of pathological gambling, especially 
substance abuse (Petry and Weinstock, 2007) but also mental illness, especially depression and anxiety disorders (Grüsser et al., 2007), at times sufficiently severe to end in suicide (Ledgerwood and Petry, 2004). Thus, pathological gamblers seem to experience a reduction in their quality of life, even though gambling yields pleasure for non-problem gamblers (Lin et al., 2010).

Relatives of pathological gamblers often suffer, too, displaying clinically relevant psychic strains and chronic stress that result for example from the tight financial situation (Dowling et al., 2014). Relationship problems and disruptions in families may ensue (Kalischuk et al., 2006).

In addition to the negative consequences for the pathological gamblers themselves and their relatives, gambling addiction also causes costs to society at large. These stem from increased social transfers due to unemployment, reduced productivity due to absenteeism or lack of concentration, and treatment costs for pathological gambling and associated comorbidities.

For these reasons, to protect consumers and especially adolescents from the addictive potential of gambling is typically the primary motivation for gambling regulation across the globe.

\subsection{Crime Prevention and Public Order}

Williams et al. (2011) and Fiedler (2016) distinguish five potential effects of gambling on crime: (1) legal gambling replaces unlicensed gambling, (2) pathological gambling leads to delinquency, (3) gambling serves as a vehicle for fraud, money laundering and match fixing (4) gambling can attract a criminal clientele, and (5) gambling can attract tourists who are either criminals themselves or targeted by criminals. The first effect can be seen as a positive externality of reducing crime. The other effects of gambling tend to raise the crime rate, although the attraction of criminals merely constitutes a geographical shift in crime and may thus be irrelevant from the aggregate perspective.

Macro-level studies on casinos and the absolute amount of crime have found a positive correlation (e.g. Hakim and Buck, 1989, Piscitelli and Albanese, 2000, Grinols and Mustard, 2006), whereas studies on the crime rate did not (e.g. Stokowski, 1996, Philander and Bernhard, 2012). These studies, however, cover only physical crimes. Micro-level studies based on surveys found that between $27 \%$ and $90 \%$ of pathological gamblers have committed crimes to finance their addiction, although these effects may also be caused by an unobserved third variable, e.g. impulsivity.

Gambling operators face a fundamental incentive to defraud the players by manipulating the games. Periodic checks of the random number generators used in regulated gambling can effectively prevent such type of fraud. In unregulated gambling, the risk of fraud provides a rationale to either impose regulation or enforce the prohibition.

Gambling is a popular vehicle for money laundering because of the large money flows, the risk being especially high in online gambling (Banks, 2012). Brooks (2012) finds that legal online gambling holds little potential for money laundering. Fiedler (2014) agrees and argues that the main potential for money laundering lies with illegal gambling. According to Fiedler et al. (2017), money laundering is most likely to be committed by operators, rather than by players.

Finally, match fixing occurs when criminals bribe players or referees to unduly influence the outcome of a sports event in order to shift the betting odds at the expense of regular punters. Apart from the financial damage to bettors, match fixing compromises the integrity of sports, which is a public good consumed by large parts of the population (IRIS, 2017).

\subsection{Fiscal motives}

Public revenues derived from gambling have been used to finance projects such as the Great Wall or Harvard University and continue to provide a major support to public budgets in many countries today. Collecting public funds is the most cited effect in studies on the social effects 
of gambling (Williams et al., 2011). The state can generate income from gambling by (1) offering gambling, for example as a state monopolist, or by collecting (2) license fees, (3) special taxes or (4) regular corporation taxes from private gambling operators, (5) income taxes from their employees and (6) on the players' winnings. Many studies have shown a positive gross effect of gambling on public funds (e.g. Clynch and Rivenbark, Settles, 2008, Williams et al., 2011). Because of the opportunity costs in the form of taxes not incurred on goods and services that the gamblers could have bought instead, the net effect is lower but likely still positive since taxation on gambling is usually higher than on other consumer goods. It should be noted, however, that taxation constitutes mere redistribution and therefore has no direct effect on social welfare. Yet an indirect benefit springs from the fact that gambling taxes have the effect of a Pigouvian tax, reducing the demand for gambling and internalizing negative externalities.

\section{Idiosyncrasies of Online Gambling Markets}

It could be argued that online gambling should be regulated more strictly than offline gambling because the former appears to be even more addictive, which would suggest greater net social costs. The share of pathological gamblers is indeed higher in online gambling (e.g. Griffiths et al., 2009, McBride and Derevensky, 2009, Wood and Williams, 2011). Yet these findings have nothing to say on causality: It may simply be the case that online gambling attracts players who by their very nature were at greater risk of addiction in the first place. This possibility is supported by Griffiths et al. (2009), who find that online gamblers are younger and more likely to be male than offline players - two characteristics that are commonly associated with a greater appetite for risk.

However, higher addictiveness of online gambling is plausible also on theoretical grounds for a number of reasons (Adams and Fiedler, 2008). Most importantly, online gambling is distinguished by its vastly increased availability. This translates into reduced non-monetary costs of playing, i.e. greater convenience, which is the major reason for players to prefer online over offline gambling (Gainsbury et al., 2012). Availability in this context has two dimensions. Firstly, time: The fact that the games are available 24/7 every day of the year leads to online gamblers playing more often, for longer periods and more types of games than their offline counterparts (ibid.). Secondly, location: Especially with the spread of mobile devices, players may gamble online wherever they want. This may be why online gamblers tend to consume more alcohol and other drugs while playing (ibid.), which exacerbates the risk of loss of control and excessive gambling.

Moreover, online gambling is also cheaper in monetary terms. Online gambling operators require very little staff, no physical venue is involved, and the company may be headquartered wherever the regulatory and tax regime is most favorable. These cost savings in relation to offline gambling are passed on to the players in the form of higher payout ratios and special offers, with the latter often serving to mask the true cost of gambling. On both accounts, the amount of gambling consumed is increased.

Gambling online is an altogether different experience. Being anonymous, the player is not exposed to other individuals as she would be in a casino or arcade, and she is able to conceal any gambling habit more easily from her family and friends: Online gambling does away with many of the checks and balances of social life that can help to prevent compulsive gambling. Furthermore, the frequency of play is usually much greater in online gambling as there are no delays due to physical processes such as dealing the cards, and players may participate in several games at once.

Online gambling being a fully electronic product, vast amounts of data can be collected pertaining to a player's gambling record and personal details - for better or worse. On the downside from the perspective of compulsive gambling, the operator may use that knowledge for tailored 
advertising especially for vulnerable players, bonus offers that entice a player to continue gambling when she appears to be on a winning streak or special schemes that aim to hide her losses. A 'suitable' combination of such strategies, which are only viable in online gambling, can promote a state of 'flow', in which the gambler all but forgets about the costs of her actions.

While a greater addictive potential of online gambling has a bearing on the substance of regulation (suggesting a tighter stance than for offline gambling), the idiosyncrasies of online gambling additionally also matter to the enforcement of any regulation. Being of a virtual nature, online gambling is almost borderless, so it becomes much harder to hold operators liable that are located in an offshore jurisdiction and operate globally. Regulators are concerned that such operators may violate consumer protection standards, inflate their reported revenues to launder money, or be used for match fixing. On the upside, though, the regulation of online gambling may in fact be simpler to enforce in some respects. The abundance of electronic data makes it easier for the operator to implement and enforce responsible gambling tools, e.g. (self-)limitation and the exclusion of minors, and it also facilitates the regulator's monitoring of the operator, e.g. to prevent fraud. Aided by the fact that cash payments are not an option in online gambling, the electronic records furthermore help to combat money laundering. Indeed, controlling the electronic payment streams between players and operators is a major strategy in enforcing a (partial) ban of online gambling, a strategy pursued for example in the US under the Unlawful Internet Gambling Enforcement Act.

\section{Conclusion}

This paper has reviewed the rationale to regulate gambling in general and online gambling more specifically. While most of the existing literature continues to focus on offline gambling regulation, online games are rapidly becoming the dominating choice. Furthermore, online gambling exhibits a number of idiosyncrasies that yield several implications. Amongst other effects, online gambling is likely to be even more addictive, thus entailing greater social costs and suggesting a firmer regulatory stance compared to offline gambling. In turn, the enforcement of online gambling regulation is going to be easier in some respects (e.g. the availability of vast amounts of electronic information) but more difficult in other respects (e.g. offshore jurisdictions). Clearly there is a research gap regarding optimal online gambling regulation.

The same conclusion may also be reached from a slightly different angle. The current regulatory responses to the growth and particularities of online gambling - a product that is essentially homogeneous around the world - are remarkably diverse: For example, Denmark has a laissez-faire approach with a liberal licensing system for online gambling with few restrictions, while Norway, a socio-economically similar neighbor country with a common regulatory history, operates a state monopoly on online gambling and accordingly bans all private operators.

Such differences are astounding considering that the social costs of online gambling are unlikely to vary much between countries, and neither are the social values towards gambling, i.e. the weights attached to those costs, all that different among Western cultures. This is confirmed by the similar regulatory goals stated in each jurisdiction. And yet we even see stark differences between regulatory approaches applied within a single nation state, where values and costs ought to be nearly identical. For example, the state of Pennsylvania grants licenses for all sorts of online games while its neighbor state New York prohibits most forms of online gambling.

If we largely rule out variations in social costs and values as explanations of such differences in regulatory approaches, we are left with only two candidates: local political constellations, and insufficient knowledge on the subject matter. The second one can and should be addressed by additional research into the socio-economic effects of different regulatory models for online gambling. 


\section{References}

Adams, M., and Fiedler, I. (2008) Zur Notwendigkeit des Verbots von Internetglücksspielen, Zeitschrift für Wett- und Glücksspielrecht, 3(4), 232-235.

Banks, J. (2012) Online gambling and crime: A sure bet?, The Ethicomp Journal.

Braun, B., Ludwig, M., Kraus, L., Kroher, M., and Bühringer, G. (2013) Outpatient Addiction Care for Pathological Gamblers in Bavaria: Do Treatment Services Meet Clients' Needs? Suchttherapie, 14(01), 37-45.

Brooks, G. (2012) Online gambling and money laundering: „Views from the inside“, Journal of Money Laundering Control, 15(3), 304-315.

Clynch, E. J., and Rivenbark, W. C. (1999) Need money? Roll the dice, International Journal of Public Administration, 22(11,12), 1681-1703.

Crane, M., Byrne, K., Fu, R., Lipmann, B., Mirabelli, F., Rota-Bartelink, A., Ryan, M., Shea, R., Watt, H., and Warnes, A. M. (2005) The Causes of Homelessness in Later Life: Findings From a 3-Nation Study. The Journals of Gerontology: Series B, 60(3), 152-159.

Danish Gambling Authority (2018) Annual Report 2017, available at: https://spillemyndigheden.dk/sites/default/files/filer-tildownload/danish_gambling_authority_-_annual_report_2017.pdf

Dowling, N. A., Rodda, S. N., Lubman, D. I., and Jackson, A. C. (2014). The impacts of problem gambling on concerned significant others accessing web-based counselling. Addictive Behaviors, 39(8), 1253-1257.

Fiedler, I. (2014) Online Gambling as a Game Changer to Money Laundering. In Ötsch, W.O., Grözinger, G., Beyer, K.M. and Bräutigam, L. (Eds): The Political Economy of Offshore Jurisdictions. Metropolis: Marburg, 79-95.

Fiedler, I. (2016) Glücksspiele: Eine verhaltens- und gesundheitsökonomische Analyse mit rechtspolitischen Empfehlungen. Peter Lang Verlag: Frankfurt am Main.

Fiedler, I., Krumma, I., Zanconato, U. A., McCarthy, K. J., and Reh, E. (2017) Das Geldwäscherisiko verschiedener Glücksspielarten. Springer Gabler: Wiesbaden.

Gainsbury, S., Wood, R., Russell, A., Hing, N., and Blaszczynski, A. (2012). A digital revolution: Comparison of demographic profiles, attitudes and gambling behavior of Internet and non-Internet gamblers, Computers in Human Behavior, 28, 1388-1398.

Gambling Commission (2018) Review of online gambling. available at: www.gamblingcommission.gov.uk/PDF/Online-review-March-2018.pdf

Griffiths, M., Wardle, H., Orford, J., Sproston, K., and Erens, B. (2009) Sociodemographic correlates of Internet gambling: Findings from the 2007 British gambling prevalence survey, CyberPsychology and Behavior, 12, 199-202.

Grinols, E. L., and Mustard, D. B. (2006) Casinos, crime and community costs, Review of Economics and Statistics, 88(1), 28-45.

Grüsser, S. M., Plöntzke, B., Albrecht, U., and Mörsen, C. P. (2007) The addictive potential of lottery gambling, Journal of Gambling Issues, 19, 19-28.

Hakim, S., and Buck, A. J. (1989) Do casinos enhance crime, Journal of Criminal Justice, 17(5), 409-416.

IRIS (2017) Preventing criminal risks linked to the sports betting market. Institut de Relations Internationales et Stratégiques: Paris.

Kairouz, S., Fiedler, I., Monson, E., and Arsenault, N. (2018) Exploring the Effects of Introducing a State Monopoly Operator to an Unregulated Online Gambling Market, Journal of Gambling Issues Issues, 37, 136-148.

Kalischuk, R. G., Nowatzki, N., Cardwell, K., Klein, K., and Solowoniuk, J. (2006) Problem gambling and its impact on families: A literature review, International Gambling Studies, 6(1), 31-60. 
Ledgerwood, D. M., and Petry, N. M. (2004) Gambling and suicidality in treatment-seeking pathological gamblers, The Journal of Nervous and Mental Disease, 192, 711-714.

McBride, J., and Derevensky, J. (2009) Internet gambling behavior in a sample of online gamblers, International Journal of Mental Health and Addiction, 7, 149-167.

Lin, E. Y. J., Casswell, S., Easton, B., Huckle, T., Asiasiga, L., and You, R. Q. (2010) Time and money spent gambling and the relationship with quality-of-life measures: A national study of New Zealanders, Journal of Gambling Issues, 24, 33-53.

Petry, N. M., and Weinstock, J. (2007) Comorbidity and mental illness. In Smith, G. Hodgins, D.C and Williams, R.J. (Eds): Research and Measurement Issues in Gambling Studies, Academic Press: Burlington.

Philander, K. S., and Bernhard, B. J. (2012) Informing the Public Debate: Academic Research on Crime and Casinos. UNLV International Gaming Institute: Las Vegas.

Piscitelli, F., and Albanese, J. S. (2000). Do casinos attract criminals? A study at the CanadianU.S. border, Journal of Contemporary Criminal Justice, 16(4), 445-456.

Settles, T. (2008) Cashing in: A view of one state's experiences with commercial gaming and moral hazard, Public Integrity, 10(4), 301-316.

So, H., and Kwok, N. (2006) No longer an entertainment: Social cost of problem gambling in Hong Kong. IEF Rehabilitation Centre for Problem Gamblers \& Hong Kong Gambling Watch: Hong Kong.

Steppan, M., Künzel, J., and Pfeiffer-Gerschel, T. (2010) Suchtkrankenhilfe in Deutschland 2009, Institut für Therapieforschung: München.

Stokowski, P. A. (1996) Crime patterns and gaming development in rural Colorado, Journal of Travel Research, 34(3), 63-69.

Williams, R. J., Rehm, J., and Stevens, R.M. (2011) The Social and Economic Impacts of Gambling. Canadian Consortium for Gambling Research: Toronto.

Wood, R. T., and Williams, R. J. (2011) A comparative profile of the Internet gambler: Demographic characteristics, game-play patterns, and problem gambling status. New Media and Society, 13, 1123-1141. 